\title{
Ensino em Ciências, Educaçáo Ambiental e Práticas Corporais: um relato de experiências no/do IFRJ-VR
}

\section{Education in Science, Environmental Education and Practice Body: an Experience Report in IFRJ-VR}

\author{
Marcelo Paraiso Alves ${ }^{1}$ \\ Wagner Francisco Marinho Silva ${ }^{2}$ \\ Paulo Roberto de Araújo Porto ${ }^{3}$ \\ Fábio Murat do Pilar ${ }^{4}$
}

\section{Resumo}

O relato de experiência configura-se a partir de dois objetivos que se complementam: apresentar e divulgar as açóes pedagógicas desenvolvidas no curso de Automação Industrial do IFRJ-VR no Ensino em Ciências da Saúde e Educação Ambiental (EA); segundo, discutir a interdisciplinaridade como um caminho possível para repensar a formação continuada de professores a partir do olhar reflexivo sobre as práticas pedagógicas no IFRJ-VR. A questão central funda-se na EA e no entendimento da relação indissociável entre a sociedade e a natureza. O relato de experiência se estruturou por meio da ação interdisciplinar entre as áreas de Educação Física, Geografia, Biologia e Filosofia, implantadas no curso de Automação Industrial do IFRJ-VR na intenção de estabelecer outros olhares para a EA, acarretando possíveis alteraçóes na concepção de currículo, dos processos teórico-metodológicos em decorrência da concepção do processo avaliativo e, finalmente, no processo de ensino no cotidiano escolar. As açôes se estruturam a partir dos seguintes conceitos: modernidade, Lazer, práticas corporais e EA, como eixos temáticos, e a interdisciplinaridade como método e como princípio filosófico-pedagógico norteador do processo de ensino-aprendizagem. Nesse sentido, a metodologia do trabalho se desenvolveu em dois momentos: Primeiro, na visita ao museu do Parque Nacional de Itatiaia, na intenção de permitir o acesso dos alunos a conhecimentos específicos e comportamentos adequados em uma área de proteção; Segundo, na escalada do Morro da Urca na tentativa de uma interação dos múltiplos campos do saber envolvidos e a experiência com diferentes práticas corporais.

Pavavras-chave: Ensino em Ciências da Saúde; Interdisciplinaridade; Formação de professores; Educação Ambiental.

\section{Abstract}

The experience report is configured from two complementary goals: to present and disseminate educational actions developed in the course of the Industrial Automation IFRJ-VR in Education in Health Sciences and Environmental Education (EE), and second, to discuss the interdisciplinary as a possible way to rethink the continuing education of teachers from the look on reflective teaching practices in IFRJ-VR. The central question is based on the EE and in understanding the inseparable relationship between society and nature. The experience report is structured through interdisciplinary action between the areas of Physical Education, Geography, Biology and Philosophy, established in the course of the Industrial Automation IFRJ-VR with the intention of establishing another look at the EE, leading to possible changes in design curriculum, theoretical and methodological processes due to the design of the evaluation process, and finally in the process of teaching in the school routine. The activities are structured from the following concepts: modernity, Entertainment, EE and bodily practices, such as themes, and interdisciplinary as method and as a philosophical and pedagogical principle guiding the process of teaching and learning. In this sense, the methodology of work developed in two stages: First, the museum visit the National Park of Itatiaia, in an attempt to allow students' access to specific knowledge and appropriate behavior in a protected area; Second, the escalation of Morro da Urca in an attempt to interaction of multiple fields of knowledge and experience involved with different body practices.

Keywords: Education Health Sciences, Interdisciplinary, Teacher Training, Environmental Education.

\footnotetext{
1 Doutor em Educaçấo.

2 Mestre em Educação.

3 Mestre em Filosofia.

4 Mestre em Ciências Biológicas.
} 


\section{INTRODUÇÃO}

O presente relato de experiência faz parte da pesquisa ESPORTE, HOMEM E NATUREZA: POR UMA REEDUCAÇÃO AMBIENTAL, Projeto Voluntário de Iniciação Científica (PIVICT) aprovado pelo Comitê de Ética do Instituto Federal do Rio de Janeiro, e configura-se a partir dos seguintes objetivos gerais: identificar a ruptura na relação do homem com a natureza; segundo, discutir o paradigma moderno e suas consequências para a sociedade atual. Refletir sobre a referida cisão (homem e natureza), nos remeteu a pensar em objetivos específicos que nos permitisse realizar intervenções no cotidiano por nós vivenciado (IFRJ campus Volta Redonda). Dessa forma, em relação aos objetivos específicos, optamos por trabalhar com os seguintes direcionamentos: elaborar estratégias metodológicas com princípio interdisciplinar, entrelaçando os conhecimentos científicos desenvolvidos no IFRJ-VR (mais especificamente nas disciplinas de Geografia, Filosofia e Educação Física) para a constituição de uma educação ambiental; e propor estratégias para o ensino em ciências no ensino médio.

O contexto no qual a experiência aqui relatada se dá é o curso de automação industrial do Instituto Federal do Rio de Janeiro campus Volta Redonda (RJ). Como parte de um projeto de ensino e extensáo com caráter interdisciplinar, implementado na forma de Visitaçáo Técnica, Ensino de Ciências e Esporte na Natureza, este trabalho vem sendo desenvolvido desde agosto de 2009, nas disciplinas de educação física, geografia, filosofia e biologia do curso de automação industrial envolvendo estudantes e professores do referido curso desta instituição. Neste trabalho, são feitas descriçóes e discussóes de uma das intervençóes deste projeto em duas direçóes: primeiro, no sentido da promoção de um conjunto de iniciativas e de propostas, que contenham elementos para uma revisão crítica do modelo moderno de percepção da realidade e, na medida em que as concepçóes pedagógicas atuais dependem desse modelo, estendendose também à formação docente, especialmente à formação continuada (o professor "prático reflexivo"), e, a uma formação voltada para educação ambiental.

No que diz respeito a essa prática docente, o que queremos é refletir sobre as açóes realizadas tendo como base as atitudes que requer um compromisso político como intelectual transformador: iniciativa, colaboração, experimentação, interesse em trabalhos sociais (TARDIF, 2002). E o segundo direcionamento se encaminha na perspectiva do ensino em ciências. É relevante ressaltar que o relato de experiência se inscreve na ótica de repensar as possibilidades de estratégias para o ensino em ciências. Essa perspectiva tem por centralidade o fato de que o ensino em ciências no Brasil (KRASILCHIK, 1987; GIL-PEREZ, 2006) vem sendo motivo de discussóes e reflexôes na comunidade científica e no contexto do sistema educacional: a falta de experimentação, o ensino conteudista, a carência de relaçóes com o cotidiano nas situaçóes de ensino e de aprendizagem, a grade curricular como uma camisa de força, que dificulta o desenvolvimento do trabalho criativo do docente, bem como o modelo de transmissão e de recepçáo dos conhecimentos científicos como verdades neutras e absolutas, levam às dificuldades de superação das concepçôes prévias e alternativas trazidas pelos alunos, às lacunas na formação inicial do professor, à dificuldade de se implementar a formação continuada, somados ao contexto estrutural muitas vezes desfavorável que envolve as escolas e o próprio sistema educacional (BRAZ DA SILVA, 2008).

Portanto, este trabalho consiste em apresentar e discutir os resultados de uma estratégia didática, tendo por base a relação entre aprender e ensinar, visando, através da mediação pedagógica, uma dinâmica construtiva de práticas alternativas nas escolas.

$\mathrm{Na}$ intenção de atingir tal objetivo, dispomo-nos, num primeiro momento ou inicialmente, a refletir sobre os fundamentos em que, sobretudo a partir do século XVII, estabeleceram-se as bases do pensamento moderno e da racionalidade na concepção da realidade, por cujo processo a relação entre o homem e a natureza sofreu uma forte interferência. No segundo momento, o esporte na natureza como um possível espaço para repensar o paradigma moderno. E por fim a apresentação e a discussão das práticas pedagógicas que emergiram do projeto em questão.

\section{CONSCIÊNCIA E VIDA}

Refletir sobre possíveis intervenções no processo de ensino no âmbito da Educação Ambiental e no Ensino de Ciências requer pensar na maneira como a sociedade atual e em decorrência o homem, se relaciona com o seu entorno e com seu meio.

Neste sentido, torna-se relevante pensar nas origens do referido processo. A ruptura homem e natureza se inicia na modernidade, a partir do pensamento cartesiano que passa a ter um papel central na sua filosofia em busca da verdade. Com isso antigos preceitos passaram a ser questionados e investigados, possibilitando assim a instituição do questionamento de dogmas, até então mantidos intocados influenciado pelos pensamentos teocêntricos. A dúvida adquire, então, uma enorme importância no pensamento cartesiano, já que será a partir dela que o referido paradigma começará a fundamentar a compreensão da realidade, sendo que o saber transmitido por outros ao longo de sua vida, não poderia ser considerado um conhecimento científico, uma vez que não foi lastreado pelo rigor científico. 
A partir desse contexto, seria necessário repensar antigas opiniōes a fim de não cometer erros, fazendo-se mister então, ouvir a razão (o método) daí verifica-se a intenção do referido paradigma: a criação de um método próprio que lhe assegurasse o domínio de todas as variáveis na busca da compreensão de todos os fenômenos que cercam o homem. Nessa perspectiva o método cartesiano dicotomiza sujeito e objeto, por intermédio da matematização da realidade.

A linguagem matemática foi concebida como sendo a única forma de interpretação da realidade. Nessa lógica, a rigidez é quase a norma, e a fragmentação às menores parcelas torna-se uma exigência, na tentativa de evitar tomar o falso por verdadeiro. Porém, para Moreira (2006), essa ruptura, teve a sua origem antes de Descartes.

Para o autor, foi no início do século XVI que Nicolau Copérnico (1473-1543) desenvolveu sua teoria heliocêntrica, colocando em dúvida a teoria de que a Terra é o centro do Universo (teoria geocêntrica). Rompe-se, assim, a concepção de mundo do homem. Este passa a ter que repensar as suas crenças e a si mesmo, uma vez que agora ele não mais se encontra no centro da Terra, lugar destinado a ele para "experimentar a onipresença, a onipotência e a onisciência e assim se orientar e se reencontrar com Deus" (MOREIRA, 2006, p.55).

Outro pensamento que contribui para um grande dilema foi a divisão aristotélica entre o mundo supra-lunar e o sub-lunar. Segundo Gomes (2003), isso ocorre a partir de Galileu Galilei (1564-1642) ao demonstrar os corpos terrestres regidos pelas leis mecânicas dos corpos celestes. Diante desse contexto percebe-se que antes mesmo de Descartes rupturas já estavam ocorrendo. A partir dos pensadores supracitados a concepção de natureza começa a ser transformada, dando início à cisão homem e natureza. Esta se consolida com Descartes e sua ótica de realidade, onde sujeito (homem) e objeto (natureza) são colocados opostamente um em relação ao outro. Rompe-se assim a relação homem e natureza, passando esta, dentro do sistema cartesiano, a ser um sistema de leis matemáticas (GOMES, 2003, p.71).

Em decorrência dessa lógica de pensamento, inaugurase a visão da natureza como máquina e a postura dominadora do homem sobre esta natureza (BARTHOLO, 1986). Com a perspectiva mecanicista, instaurada pela modernidade, a natureza é subalternizada pela técnica científica, agora denominada: tecnologia.

É com modernidade que a cientificidade converte-se a um único critério de verdade revigorando a concepçáo de que a ciência moderna é fruto de todo este processo histórico. Como boa parte do Ensino Médio contempla este recorte temporal, os alunos devem compreender todo o contexto em que foi produzido o conhecimento com o qual estão travando múltiplos diálogos. A compreensão do ambiente cultural é fundamental para a compreensão das respostas dadas pelos homens ao longo da História aos problemas com que se defrontaram. Dessa forma, vale a pena atentar-se para a relação homem, natureza e o esporte na tentativa de exemplificar como a interdisciplinaridade pode se dar a partir da discussão do processo de construção histórica de qualquer conhecimento. Assim a Biologia, Filosofia, Educação Física e Geografia que tem grande importância no currículo, serão as disciplinas que nos daráo suporte para a uma possível mudança na concepção dos futuros trabalhadores permitindo uma visão de mundo em que se considera as relaçóes entre ciência, natureza, tecnologia, sociedade e em decorrência os seus modos de vida. Portanto, o discente do referido curso deverá ter ao concluir seu curso uma importante ferramenta de compreensão do mundo do trabalho e da sociedade da qual fará parte.

Pensar a prática pedagógica e em decorrência o Ensino de Ciências (KRASSILCHIK, 1996) a partir da ótica ressaltada, requer conceber a história e a filosofia da ciência para além da mera ilustração, um ensino que parta de uma concepção histórico-filosófica que poderá auxiliar na tomada de posição crítica diante deste discurso. Isto porque os estudantes conhecerão o processo de construçáo histórico da ciência, com suas discussóes e interpretaçôes, relativizando a visão de neutralidade da ciência.

\section{ATIVIDADES NA NATUREZA: POSSÍVEIS ARTI- CULAÇÓES COM A EDUCAÇĀO AMBIENTAL}

Partindo do referido pressuposto, buscamos a novas práticas corporais relacionadas às questóes ambientais que tem possibilitado abertura para novas mentalidades, engendrando uma diversidade de práticas; dentre elas as práticas corporais em Áreas de Proteção Ambiental (APA).

$\mathrm{O}$ projeto em questáo não possui a pretensão de estabelecer a discussão dos movimentos ambientalistas. $\mathrm{O}$ que procuramos, neste estudo, é enfocar questóes relacionadas a práticas corporais, especificamente as esportivas, nas quais se manifestam várias contradiçóes. Por exemplo: $\mathrm{Na}$ sociedade atual há uma tendência de conceber uma espécie de reciclagem da natureza (Baudrillard apud Marinho, 2001). A natureza é reduzida ao estado de enquadramento do tecido urbano. A autora parte do pressuposto de que o reducionismo mencionado emerge no contexto social em forma de espaços verdes, de reservas naturais, dentre outros. Essa perspectiva privilegia um modelo que simula à presença original da natureza, sendo esta condenada a um sinal meramente efêmero.

Outra ambiguidade que se apresenta e nos remete às aproximaçóes e valorizaçóes crescentes com relação à natureza são os aspectos econômico, político, social e esportivo, 
ou seja, além do processo de reciclagem da natureza, já mencionado, ela ainda é veiculada pela mídia, aparentando estar sendo vendida pelo mercado e pelas indústrias de entretenimento, reduzindo-se a um símbolo de consumo.

Para Marinho (2001) especificamente, no caso das atividades esportivas realizadas em ambientes naturais, em sua grande maioria, é concebida como mera satisfação trazida que se relaciona a uma condição de (pseudo) aventura, acarretando a redução na forma como se estabelece a relação entre o praticante e a natureza (sujeito e objeto). A natureza - objeto -, partido dessa lógica, passa a ser encarada como um mero local de atividades, cujo objetivo é limitado, servindo às necessidades do "sujeito" que pratica e procura satisfazer o seu prazer. Assim, a natureza, a partir de tal distorçáo, fica relegada a um segundo plano, como um ambiente coincidentemente útil, conveniente para a realização das atividades esportivas. Nessa ótica, o conhecimento e a educação ambiental parecem ser irrelevantes.

Com foco nas atividades realizadas em APA's, o referido relato pretende apontar algumas pistas que enfatizam o lazer, o esporte e a educação ambiental como espaços privilegiados para o processo de mudança do modelo paradigmático que influencia as condiçôes de vida atuais. Não isoladamente, mas em estreita relação com outros campos de atuação e formação, potencializando a participação e o engajamento crítico e criativo da comunidade escolar.

Partindo do referido pressuposto, Guimarães (2006), ressalta o reconhecimento generalizado do mundo em relação aos aspectos vinculados aos problemas ambientais e nos remete a pensar que esse reconhecimento já é um avanço, entretanto, não basta, é preciso intervir no processo de transformaçôes ambientais na tentativa de superação do modelo de produção da sociedade atual.

A questão fundamental da Educação ambiental é entender a relação indissociável entre a sociedade e a natureza. É no bojo desta relação que emerge a discussão ambiental com questionamentos e dúvidas sobre a forma como essa relação vem se constituindo. Historicamente é possível apontar a forma de utilização do espaço natural socialmente construído e o manejo dos recursos naturais como eixo central das discussóes que envolvem a atual crise ambiental.

A compreensão da relação homem-natureza tem sido tema central nas reflexóes sobre o agravamento acelerado da crise ambiental que se tem vivido nas últimas décadas, especialmente no que diz respeito ao antagonismo que contém e que é criado pela organização da produção econômica na sociedade moderna (TOZONI-REIS, 2004, p. 34).

O processo de aprendizagem estabelecido pela mediação entre as variadas compreensóes da experiência do indivíduo e dos coletivos sociais em suas relaçóes com o ambiente acontece particularmente pela ação do educador como intérprete dos laços entre a sociedade e o ambiente. Desta forma, educar dentro da perspectiva ambiental perfaz uma construçáo social de novas sensibilidades e posturas éticas diante do mundo.

Cabem críticas ao trabalho pedagógico feito sobre o meio ambiente cujo enfoque resume-se à compreensão de que somente aquilo que é natureza deve ser entendido como meio ambiente e cujos estudos enfocam somente os problemas ambientais. "Em ambos os casos, corre-se o risco de tomar a tradição naturalista como matriz explicativa e reduzir o meio ambiente à natureza - nesse caso, visto como espaço natural, em contraposição ao mundo humano" (CARVALHO, 2004, p. 56).

Nas chamadas "trilhas ecológicas" nas quais os alunos podem entrar em contato com a natureza por exemplo, fica evidenciado que haverá somente uma difusáo dos conhecimentos da Biologia ou da Biogeografia. Do ponto de vista pedagógico, tal proximidade com meio proporciona apenas uma leitura explicativa e não interpretativa da realidade impregnada de relaçóes complexas e diversificadas.

Não é o caso de negar a importância das ciências biológicas para a Educação Ambiental, mas de não reduzir o conhecimento do complexo à simples informaçóes ensinadas pelas leis da Física ou da Biologia, deixando de entender as relaçôes que são constituídas no meio ambiente. É o caso em que o aprendizado se dá apenas por conceitualizaçóes sem aplicar-lhes um caráter mais interpretativo, sem estabelecer relaçôes entre os fenômenos observados.

A partir desta ótica em que o entendimento do meio é reduzido à explicação e difusão de verdades incontestáveis das Ciências Naturais por parte dos educadores não permite uma leitura mais interpretativa da realidade e não proporciona aos educandos estabelecer relaçóes entre o conhecimento e o meio em vivem (CARVALHO, 2004).

Enfim, nesta visão objetivada do meio ambiente que se pode chamar naturalista, não existe espaço para "educadores e aprendizagens processuais significativas, reflexivas, críticas" (CARVALHO, 2004).

Uma aprendizagem significativa requer uma compreensão entre as concomitantes relaçóes entre a sociedade e a natureza a partir da construção de um conhecimento dialógico destes dois.

O mergulho no diálogo entre sociedade e natureza, tomado como uma interação permanente em que as partes se modificam mutuamente, possibilita uma compreensão dinâmica dessa relação. Ao privilegiar a compreensão do humano nas interaçôes com a natureza, está-se recusando instituí-lo no alto de uma razão observadora e decodifica- 
dora. Bem ao contrário desta visão objetivista - de acordo com o qual interpretar o meio ambiente seria captá-lo em sua realidade factual, descrever suas leis, mecanismos e funcionamento - trata-se, segundo uma concepção interpretativa, de evidenciar os horizontes de sentidos histórico-culturais que configuram, em um tempo específico, as relações de determinada comunidade humana com o meio ambiente (CARVALHO, 2004, p. 121).

$\mathrm{Na}$ perspectiva interpretativa, o meio ambiente é o local onde se estabelecem relaçóes interativas entre a sociedade humana e a natureza, sem dissociá-los enquanto realidade holística e sistêmica. A Educação torna-se, deste ponto de vista, um processo no qual o sujeito torna-se ativo construtor do conhecimento a partir do mundo sensível e vivido. O sujeito começa a interpretar a realidade a partir da experiência que tem com o mundo aprendido e vivido por ele, entendendo o sentido da própria existência e modificando-se um ao outro. Esta faceta da aprendizagem interpretativa torna-a mais significativa e permite a abertura para novos conhecimentos, experiências e aprendizados.

Neste sentido o sujeito e o objeto apreendido constroem uma relação dialética.

A verdade da experiência contém sempre a referência a novas experiências. Nesse sentido, a pessoa que chamamos experimentada náo é somente alguém que se fez o que é através das experiências, mas alguém que está aberto a novas experiências. [...] A dialética da experiência tem sua própria consumação não num saber concludente, mas nessa abertura à experiência que é posta em funcionamento pela própria experiência (GADAMER, 1998, p. 52).

Assim, partindo dos pressupostos abordados por Gadamer (1998), Carvalho (2004) e Tozoni-Reis (2004), buscamos o esporte na natureza na intenção de propiciar a aprendizagem significativa para os alunos do IFRJ-VR.

$\mathrm{Na}$ intenção de atingir os objetivos propostos, por agora consideramos relevante diferenciar alguns conceitos.

O conceito de esporte de aventura ainda é novo no Brasil. Por isso, o termo "esportes radicais" é usado indiscriminadamente para se referir a essa atividade. Embora alguns esportistas pratiquem algumas dessas atividades em situaçóes que exijam grande habilidade, em geral, os esportes de aventura são praticados por pessoas comuns que buscam uma aproximaçáo com a natureza ou com espaços alternativos para a prática esportiva. Para Dias $(2009 ; 2010)$ a aproximação ou enredamento das práticas corporais à natureza não é recente, pois está ligada a uma trajetória histórica de uma multiplicidade de experiências desenvolvidas em outros tempos e espaços (alpinismo, esqui, iatismo, canoagem, dentre outros), porém as formas mais recorrentes como tais atividades (mountain bike, voo livre, windsurf, snowboard e outros) têm ocorrido estão despertando, cada vez mais, novos interesses e olhares.

Assim, na intenção de especificar as práticas sócio-culturais a que nos referimos no estudo, vamos considerar as práticas corporais realizadas em APA's como açóes realizadas sempre ao ar livre, em contato com o meio ambiente, envolvendo a descoberta de novo local ou de um novo conhecimento. Nesta perspectiva, a referida prática não está, necessariamente, na ótica do esporte de competição (MARINHO, 2004).

Portanto, a opção pela terminologia "atividades na natureza” se deve justamente à amplitude de compreensóes e sentidos que a expressão pode abarcar. Desta forma, sem pretender reduzir e engessar o conceito, apenas delineio algumas características para melhor visualização do tema. Estou entendendo-as como práticas cercadas por riscos e perigos, na medida do possível, calculados, náo ocorrendo treinamentos intensivos prévios (como no caso dos esportes tradicionais e de práticas corporais como a ginástica e a musculação). A experimentação acontece de maneira mais direta, havendo um afastamento de rendimentos planejados (MARINHO, 2004, p. 4).

Assim, a inserção em áreas de proteção foi o termo escolhido por permitir a designação da pluralidade de práticas, realizadas privilegiadamente em momentos de lazer. Em relação ao Lazer, optamos em trabalhar com a concepção pautada na contraposição da lógica do mercado, que abarcaria as abordagens compensatória e utilitarista (MARCELLINO, 2000, p.15). Ao contrário, concebemos o lazer como um possível lócus de intervenção educativa estabelecendo novas práticas e novos conhecimentos que permitiriam, em tese, a mudança de valores e concepçóes de mundo, possibilitando que o homem reestabeleça a sua relação de (inter) dependência com a natureza.

As atividades em APA's ainda possuem em suas manifestações algumas características importantes de serem ressaltadas: são realizadas em diferentes locais dos esportes tradicionais, assim como as condiçóes de prática, os objetivos e em decorrência a motivação estão fundados em outros princípios que não os da competição exacerbada, e por fim, os meios utilizados para o seu desenvolvimento, além de necessários para a proteção e segurança de seus praticantes, também são de caráter inovador, pois os equipamentos tecnológicos possibilitando uma fluidez entre os praticantes e o meio ambiente. Para Marinho e Inácio (2007), 
Essas atividades estão envolvidas por emoçóes e sentimentos que extrapolam suas formas e conteúdos, pois se relacionam a rituais, mitos, temores. São muitos os termos que vêm sendo utilizados atualmente para representar essas formas de expressôes humanas na natureza (pp. 60 e 61).

A partir dos referidos autores, entendemos essas práticas em seu entrelaçamento com riscos e perigos, na medida do possível planejados, havendo apenas uma preparação ou adaptação ao equipamento, não incidindo treinamentos preparatórios com o objetivo de eficiência em gesto técnico, como as preparaçōes técnico-táticas dos esportes tradicionais. Diante deste contexto cabe perguntar: Quais as possibilidades do esporte na natureza e para a educaçáo ambiental? $\mathrm{O}$ esporte na natureza abre novas possibilidades de inserçóes para a educaçấo ambiental? Quais os novos elementos presentes nesta prática corporal?

Tentando responder a essas questôes, Marinho e Inácio (2007) elencam, a partir de vários estudiosos - Marinho e Seabra (2002); Sant'Anna (2001); Cardoso et al. (2006); Betrán e Betrán (2006); Melo et al. (2006) -, as possibilidades de inserçấo da referida atividade: a transformação na relação do ser humano com o meio ambiente, a mudança das práticas pedagógicas no cotidiano escolar, a utilização da natureza como um espaço de vivências educativas e não utilitárias, mercantilistas ou de modismo, dentre outras como será apresentado no transcorrer do trabalho.

O primeiro aspecto a ser ressaltado por Marinho e Seabra apud Marinho e Inácio (2007) é apresentado através de vários estudos que discutem a possível reaproximação dos seres humanos à natureza. Para Marinho e Seabra apud Marinho e Inácio (2007), as atividades nas áreas de proteção permitem às pessoas o questionamento de suas açóes ao se depararem com o paradoxo presente na contemporaneidade: impactos causados pelo homem e potencialidades da natureza.

Os autores enfatizam que tais atividades favorecem a conscientização e a sensibilização do aluno para com o meio natural e seus problemas, promovendo uma educação ambiental baseada no conhecimento das características dos ecossistemas utilizados, no contexto sociocultural a que pertencem, na utilização responsável dos recursos materiais e tecnológicos que promovem o deslizamento controlado pelo ar, água e terra. Mais ainda, tratadas pedagógica e didaticamente, podem ajudar na tarefa de educar alunos por meio de um processo interdisciplinar (MARINHO, INÁCIO, 2007, p. 63) - grifos nossos.

Pensar a prática pedagógica a partir da visita técnica e do seu caráter interdisciplinar e transversalizante, nos remete a pensar no que Lerbert (2002), apoiado em Piaget, enuncia ao considerar a noçáo de nível epistemológico externo.

Para o autor, a referida noção - nível epistemológico externo - é aquele que póe em evidência o alcance mais amplo dos resultados alcançados pela ciência específica - educação física e atividades na natureza - quando comparada às outras ciências. Esse recorte possibilita uma quantidade específica de referenciais para a "religaçáo dos saberes" e a introdução do pensamento complexo (MORIN, 2000).

Diante dessa ótica, é possível que professores e alunos, estabeleçam relações entre saberes (educação física, geografia, filosofia) focando-se em apreender em um mesmo objeto (educação ambiental) de diversos ângulos, para permitir que o discente se dê conta objetivamente, da multiplicidade de olhares possíveis para um mesmo objeto. No entanto, no momento em que buscamos a visita técnica como ponto de partida, e não como ponto de chegada - se é que existe algum ponto de chegada? - não negamos as possibilidades de relação com o desenvolvimento cognitivo e com a abstração. Para o autor (LERBERT, 2002), Piaget trabalha com o conceito de abstração em uma perspectiva dinâmica, colocando em ação dois processos cognitivos em interação: interiorização e descentramento.

A interiorização consiste, como a própria denominação já nos faz pensar, em interiorizar os dados do mundo material, se assim podemos denominar. E o segundo processo, descentramento, que produz um enriquecimento maior, obriga o aluno a "mergulhar aquilo que foi adquirido num quadro mais vasto que conduza a uma certa relativização" (LERBERT, 2002, p. 529).

Trata-se, pois, de um tipo de realidade que somente emrge como tal a aprtir de um determinado nível de complexidade de organização biológica. Nesse sentido, existe um escoramento de uma pela outra. Mas o mais importante ainda é a noção de emergência que significa que, num dado momento, os elementos constitutivos de um sistema fazem aparecer, pela virtude da complexidade de sua organizaçâo, as propriedades e as qualidades que não existiam de modo nenhum, nem mesmo potencialmente no nível das partes isoladas (MORIN, 2002, p. 173).

Diante do exposto percebemos no entrelaçamento entre o pensamento de Lerbert e Morin (2002) a necessidade de pensar na capacidade cognitiva e, em decorrência, na abstração a partir do que se vive cotidianamente: é o ato de problematização! Antes de saber o sentido e a direção que se pode conceber a uma dada questáo, é fundamental que o aluno perceba que existe uma questáo. Portanto, a nossa pretensão é reverter o processo de ensino e aprendizagem, propondo um ensino às avessas. É permitir que o senti- 
do dos saberes seja suficientemente interiorizado e que o aluno tenha as capacidades suficientes de descentralização, propondo que o discente tenha primeiro sucesso em sua ação e, posteriormente, consiga compreender determinado fenômeno estabelecendo relaçóes com experiências vividas, implicando uma produção e não somente o consumo do conhecimento: educação bancária.

Um segundo aspecto a ser mencionado por Marinho e Inácio (2007), citando Betrán e Betrán (2006), é a perspectiva que se apresenta diante das atividades na natureza, como práticas constituintes do projeto da educação física, subsidiando novos padróes motores. Os autores consideram que as atividades requerem a utilização de novos padróes motores devido a múltiplos fatores: os novos implementos necessários a sua prática, a sensação de incerteza motora em contato com a natureza provocada por diversos contextos ambientais proporcionando oportunidades de manifestaçôes de diferentes situaçôes emocionais em inúmeras circunstâncias (estresse, dificuldade, risco).

A Educaçáo Física, particularmente, pode, por meio da experiência na natureza (ou seja, fora das quadras de cimento, dos ginásios poliesportivos, das piscinas, dos campos de futebol, etc.), potencializar suas estratégias de ação para desenvolver, nos alunos, suas habilidades motoras, capacidades físicas e, até mesmo, muitos fundamentos esportivos específicos. As corridas de orientaçáo, por exemplo, assim como a escalada, a caminhada, a canoagem e outras atividades, podem ser utilizadas para satisfazer uma variedade de objetivos educacionais, oportunizando diferentes níveis de desenvolvimento: Coletivo: habilidades cooperativas e de comunicação; Pessoal: auto-estima; Cognitivo: tomadas de decisão; resolução de problemas; Físico: aptidão e desenvolvimento de habilidades motoras. Podendo, da mesma forma, serem utilizadas como atividades de lazer, com fim nelas mesmas (MARINHO, 2004, p. 6).

A ruptura com atividades já conhecidas (esportes tradicionais) proporciona o surgimento da ação solidária entre os praticantes, pois a grande maioria dos alunos apresentam dificuldades na execução motora da atividade, no domínio dos equipamentos e no controle das açóes que emergem no decorrer das atividades: o cansaço físico, ausência de água, excesso de calor, chuva dentre outros.

Assim, fundados na experimentação de novas experiências acreditamos na possibilidade da condução dos discentes a diferentes formas de relação com o meio em que vivem. Nesta perspectiva, nos parece que a busca por estas atividades desponta o interesse e motivação, impulsionada pelo desejo de experimentar novas emoçôes, pautados na ludicidade e no caráter hedonístico.
Para Bruhns (1997) estes aspectos demonstram a necessidade de aprendizados, no que se refere à gerência e à participação em atividades na natureza requerendo um repensar sobre o meio ambiente: a prática; a conservação ambiental e o processo educativo. É importante ressaltar que os aspectos mencionados são complementares e interdependentes, pois na atualidade, é preciso que os diversos campos do conhecimento se envolvam com a educaçáo ambiental, na intenção de aprimorar os estudos, redimensionando as perspectivas atuais de educação.

\section{METODOLOGIA E DESCRIÇÃO DAS AÇÓES}

O processo de estudo a partir das visitas técnicas no IFRJ-VR e as possíveis relaçóes entre o ensino de ciências, as práticas corporais em APA's e a educação ambiental, se desenvolveu no período compreendido entre agosto e dezembro de 2009 com visitas na parte baixa do Parque Nacional do Itatiaia (PARNA), mais especificamente no Centro de visitantes e museu da fauna e flora, bom como passeio nas trilhas do parque e na escalada no Morro da Urca. As visitas técnicas nas duas áreas de proteção foram realizadas com as turmas do segundo período do curso de Automação Industrial do IFRJ - VR.

Durante o transcorrer do segundo semestre de 2009, as aulas da disciplina de Educação Física buscou discutir textos específicos sobre a inserção de grupos em área de proteção ambiental (DIAS; ALVES JÚNIOR, 2009), os cuidados que se deve ter com o meio ambiente durante a inserção de grupos e, simultaneamente, os benefícios proporcionados no âmbito da saúde e da qualidade de vida por intermédio de exercícios físicos.

Na disciplina de Geografia foram trabalhadas as temáticas relacionadas ao domínio morfoclimático, que englobam as características geológicas, climáticas e fitogeográficas do local. No caso do Parque de Itatiaia as reservas de Mata Atlântica, o clima tropical de altitude e os dobramentos antigos do relevo foram os elementos-chave.

Em filosofia o trabalho transcorreu por meio da compreensão do pensamento moderno e as consequências do referido paradigma na sociedade contemporânea.

No centro do presente relato estiveram os alunos do Ensino Médio do Curso de Automação Industrial do IFRJ - Volta Redonda.

Iniciamos a implementação do projeto de Educação Ambiental com inserçôes de textos e discussôes específicas em cada campo ou área do conhecimento: Educaçáo Física, Filosofia, Geografia. Para o estabelecimento dessa etapa foi relevante a definição do princípio filosófico que está no cerne do projeto: o caráter interdisciplinar. 
No que diz respeito ao princípio filosófico é importante frisar que desde o início dos trabalhos pedagógicos, os alunos foram informados a respeito da necessidade da configuração de um trabalho final que estabelecesse o diálogo com as áreas envolvidas no projeto.

Assim, através do diálogo entre os diversos campos do conhecimento - Geografia, Educação Física, Filosofia -, buscamos o enfrentamento com o paradigma moderno-cartesiano, tais como as dicotomias presentes na relação teoria/ prática, natureza/cultura, a perspectiva de hierarquização disciplinar, a relação utilitária com o conhecimento, dentre outras.

A constituição do projeto, dentro da perspectiva interdisciplinar, permitiu o diálogo e a tessitura plural entre as múltiplas possibilidades de olhares, nos movendo para o que Santos (2010) denomina de ecologia dos saberes.

As possibilidades e os limites de compreensáo e de ação de cada saber só podem ser conhecidas na medida em cada saber se propuser uma comparaçấo com outros saberes. Essa comparação é sempre uma versão contraída da diversidade epistemológica do mundo, já que está é infinita. É, pois, uma comparação limitada, mas é também o modo de pressionar ao extremo os limites e, de algum modo, de os ultrapassar ou deslocar. Nessa comparaçáo consiste o que designo por ecologia dos saberes (SANTOS, 2010, p. 543).

É relevante ressaltar que ao conceber a ação na ótica da ecologia de saberes, estamos considerando a assimetria que emerge entre os diferentes conhecimentos como um aspecto fundamental no trabalho interdisciplinar, pois Santos (2010) menciona que esta assimetria configura a diferença epistemológica. Para o autor, essa é uma questão complexa, por que sendo epistemológica manifesta-se com uma intensidade maior como uma questão política, isto é, ocorre simultaneamente uma assimetria de poderes.

Um aspecto importante a ser considerado, são os modos como essa assimetria é acionada na sociedade atual: a primeira consiste em maximizá-la, causando o que o autor denomina de fascínio epistêmico, isto é, considerar outras formas de conhecimento inexistente. A segunda consiste na tentativa de minimizaçáo da assimetria. Para Santos (2010) é uma ação complexa, pois não permite o envolvimento unilateral de um dado conhecimento. Ao contrário, é preciso que façam dela a mola propulsora para impulsionar o diálogo entre os campos envolvidos.

Atuar na ótica da ecologia dos saberes requer também reconhecer o conceito de "douta ignorância" (SANTOS, 2010 , p. 540). Esse conceito nos permite perceber e reconhecer a pluralidade de conhecimentos existentes no mundo e em decorrência a impossibilidade de que uma única forma de saber daria conta da infinitude dos conhecimentos do mundo. A douta ignorância, portanto, permite reconhecer a necessidade da humildade dos diversos saberes e suas limitaçôes que "póe à precisão do conhecimento que temos de coisas finitas" (SANTOS, 2010, p. 541).

Pensar na perspectiva ressaltada pelo autor possibilitou romper com o processo de hierarquização disposta no cotidiano escolar, onde estabelece a prioridade e a importância de alguns conhecimentos em detrimentos de outros, por exemplo, a discriminação histórica sofrida pela Educação Física brasileira, decorrente da dicotomia corpo e mente: paradigma cartesiano.

Essa dinâmica ensejou o pensar coletivamente na coesão entre as intervençôes dos docentes, pois não se poderíamos iniciar as visitas técnicas (visita ao museu da fauna e da flora no Parque Nacional de Itatiaia (PARNA) - Instituto Chico Mendes - e a escalada do Morro da Urca) sem estabelecer conexôes com os assuntos abordados pelos professores durante o semestre. Diante disso, elaborou-se, um cronograma com as entradas de textos (MARCELLINO, 2005; DIAS; ALVES JÚNIOR, 2009) encaminhados pelos professores. Especificamente no que diz respeito ao esporte em APA's (Educação Física) a discussão se desdobrou entorno dos cuidados nas inserçôes em áreas de proteção, a relaçấo com os hábitos cotidianos e a educação ambiental.

As visitas ocorreram no segundo semestre de 2009, mais especificamente no mês de setembro a visita ao PARNA e em dezembro a escalada no Morro da Urca.

Como propostas avaliativas foram solicitados trabalhos em grupos com caráter interdisciplinar e a produçáo de vídeo utilizando os conhecimentos adquiridos em aulas e durante o processo de visitação técnica nos espaços mencionados.

\section{CONSIDERAÇÓES FINAIS}

Ao proporcionar a inserçấo em áreas de proteção, por meio das visitas técnicas, as discussóes sobre os conhecimentos trazidos pelos estudantes em relaçáo homem e natureza e os conhecimentos adquiridos pelos discentes após as atividades supracitadas, foi possível identificar mudanças conceituais em relação seguintes aspectos: Primeiro, foi possível perceber alteraçôes no conceito de natureza, pois inicialmente os alunos apontavam como natureza um conceito restrito a ambientes intocados. A referida concepçáo não permite perceber que o homem em qualquer ambiente ou espaço geográfico em que se encontre está imerso na natureza; Segundo, diante da mudança na concepção de natureza, por parte dos alunos, percebe-se também uma mudança atitudinal, pois a partir da perspectiva em que se considera natureza todos os espaços em que o homem se relaciona com o ambiente, os discentes passaram 
a perceber a necessidade de comportamento, não só nas áreas de proteção, mas em todos os espaços em que está imerso. Terceiro, em relação ao trabalho pedagógico, interdisciplinar, foi possível romper com as práticas tradicionais de avaliação, pois a prática coletiva permite a produção de outros olhares para as produçôes discentes, por exemplo: o vídeo produzido pelos alunos durante as inserçóes nas APA's utilizando e articulando os conteúdos adquiridos nas disciplinas envolvidas (Educação Física, Filosofia, Biologia e Geografia). Por fim, é relevante ressaltar que não é intenção desse trabalho, conceber a prática corporal como o único caminho para solucionar o processo dicotômico ocasionado pelo pensamento moderno, mas propor uma ação possível para intervir no cotidiano da escola com "outras" experiências e metodologias para o Ensino em Ciências e para a Educação Ambiental.

\section{REFERÊNCIAS BIBLIOGRÁFICAS}

1. BARTHOLO JR., R. - Os Labirintos do Silêncio: Cosmovisão e Tecnologia na Modernidade. Ed. Marco Zero/Coppe/UFRJ, SP, 1986.

2. BRAZ DA SILVA, A. M. T.; METTRAU, M. B.; BARRETO, M. S. L. O lúdico no processo de ensinoaprendizagem das Ciências. Revista Brasileira de Estudos Pedagógicos, vol.88, n 220, p. 445-458, 2007.

3. CARVALHO, A. M. P. e GIL-PÉREZ, D. Formaçáo de professores de ciências: tendências e inovaçóes. 8 ed. São Paulo: Cortez editora, 2006, 120p.

4. CARVALHO, I. C. de M. Educação ambiental: a formação do sujeito ecológico. São Paulo: Cortez, 2004.

5. DIAS, C.; ALVES JUNIOR, E. Entre o mar e a montanha: esporte, aventura e natureza no Rio de Janeiro. Niterói, RJ: EdUFF, 2007.

6. DIAS, C. A. Urbanidades da natureza: o montanhismo, o surfe e as novas configuraçóes do esporte no Rio de Janeiro. Rio de Janeiro: Apicuri, 2008.

7. DESCARTES, René. Discurso do método. In: Discurso do método; Meditaçóes; Objeçôes e respostas; As paixóes da alma; Cartas. São Paulo: Abril Cultural (Col. Os Pensadores 15) 1973.

8. GOMES, P. C. C. A evolução do racionalismo moderno e o pensamento da natureza. In: Geografia e Modernidade. 4a Ed. Rio de Janeiro: Bertrand, 2003.
9. INACIO, H. L. D. et al. 'Bastidores das práticas de aventura na natureza'. In: SILVA, Ana M.; DAMIANI, Iara R. (Orgs.). Práticas corporais: experiências em Educaçáo Física para outra formaçáo humana. Florianópolis (SC): Nauemblu Ciência e Arte, 2005, v.3, p.69-87.

10. KRASIILCHIK, M. O professor e o currículo das ciências. São Paulo: E.P.U, 1987.

11. .Formação de Professores e Ensino de Ciências: tendências nos anos 90. In: MENEZES, L.C (org.). Formaçáo Continuada de Professores de Ciência. NUPES, p. 137-170, 1996.

12. Prática de ensino de biologia. 4. ed. São Paulo: Ed. da USP, p.198, 2004.

13. LERBERT, G. Transdisciplinaridade e Educação. In MORIN, E. A religação dos saberes: o desafio do século XXI. 3 ed. Rio de Janeiro: Bertand Brasil, 2002.

14. MARCELLINO, N.C. Lazer e Educação. 7. Ed. SP: Papirus, 2000.

15. MARINHO, A. Lazer, Natureza E Aventura: compartilhando emoções e compromissos. Revista Brasileira de Ciências do Esporte, v. 22, n. 2, p. 143-153, jan. 2001.

16. . Atividades na natureza, lazer e educação ambiental: refletindo sobre algumas possibilidades. Motrivivência - Revista de Educação Física, Esporte e Lazer, Florianópolis: Núcleo de Estudos Pedagógicos em Educação Física, ano XVI, n. 22, p. 47-69, jun. 2004.

17. MARINHO, A.; INÁCIO, H. L. D. Educação Física, Meio Ambiente e Aventura: um percurso por vias instigantes. Revista Brasileirade Ciências do Esporte, Campinas, v. 28, n. 3, p. 55-70, maio 2007.

18. MOREIRA. Ruy. Para onde vai o pensamento geográfico? Por uma epistemologia crítica. São Paulo: Contexto, 2006.

19. MORIN, E. \& LE MOIGNE, J. L.. A inteligência da complexidade. São Paulo: Peirópolis, 2000.

20. MORIN, E. A religação dos saberes: o desafio do século XXI. 3 ed. Rio de Janeiro: Bertand Brasil, 2002. 
21. MOSCOVICI, S. Representaçóes sociais: investigaçóes em psicologia social. Petrópolis:

Vozes, 2003.

22. TOZONI-REIS, M. F. de C. Educação ambiental: natureza, razão e história. Campinas: Autores Associados, 2004.

23. THIOLLENT, M. Metodologia da pesquisa-ação. São Paulo: Cortez, 1994.

24. UMAÑA, S. A. Las representaciones sociales: ejes teóricos para su discusión. Cuaderno de Ciências Sociales, 127. San José: FLACSO, 2002. 